\title{
LETTER
}

\section{mRNA-based SARS-CoV-2 vaccination is associated with reduced ICU admission rate and disease severity in critically ill COVID-19 patients treated in Switzerland}

\author{
Matthias Peter Hilty ${ }^{{ }^{*}}$ D , Stefanie Keiser ${ }^{1}$, Pedro D. Wendel Garcia ${ }^{1}$, André Moser ${ }^{2}$ and Reto A. Schuepbach ${ }^{1}$ on \\ behalf of the RISC-19-ICU Investigators for Switzerland
}

@ 2022 Springer-Verlag GmbH Germany, part of Springer Nature

Dear Editor,

Large-scale vaccination programs were incepted in response to the coronavirus disease 2019 (COVID-19) pandemic. Although high effectiveness was initially indicated [1], public-health factors and emerging virus variants have contributed to changes in characteristics of critically ill COVID-19 patients [2]. To monitor the effects of the vaccination program on the development of critical illness due to COVID-19, we compared the characteristics and outcome of vaccinated versus non-vaccinated patients admitted to the intensive care unit (ICU) via the prospective observational Risk Stratification in COVID-19 patients in the ICU (RISC-19-ICU) registry [3]. Mixed-model analysis accounted for potential treatment center effects, and analysis was adjusted for age, sex and immunosuppression. To minimize variation in viral epidemiology, vaccination programs and ICU resources, we focused only on patients admitted to ICUs in Switzerland (Appendix S1).

Of 4351 critically ill COVID-19 patients enrolled internationally by September 30th, 2021, 2253 were treated in Switzerland. Within this cohort, 964 patients admitted to the ICU during the vaccination program were included

\footnotetext{
*Correspondence: matthias.hilty@usz.ch

${ }^{1}$ Institute of Intensive Care Medicine, University Hospital of Zurich, Zurich, Switzerland

Full author information is available at the end of the article
}

The members of RISC-19-ICU Investigators for Switzerland are listed in acknowledgements.
(Fig. S1). 10.5 million vaccine doses were inoculated in 5.6 million individuals during this period (64.3 population-\%, Fig. S2 A/B). 33 patients were admitted to the ICU median interquartile range, (IQR) 92.5 (22.3-110.3) days after the second vaccination (3.4\% of ICU admissions, 30\% BNT162b2 [Pfizer/BioNTech], 70\% mRNA1273 [Moderna]), versus 931 non-vaccinated patients [ICU/population vaccinated-non-vaccinated ratio was 0.035/1.29, OR (CI) 0.027 (0.019-0.039), $p<0.001]$.

Comparative statistics between vaccinated and nonvaccinated patients are detailed in Fig. 1 and Table S1. Vaccinated patients were 6.8 (CI 2.0-11.6) years older $(p<0.01)$ and had more comorbidities [RR (CI) 1.5 (1.1$2.1), p=0.03$ ], especially immunosuppression [OR (CI) $5.8(2.7-13), p<0.0001]$. They presented at ICU admission with lower respiratory Sequential Organ Failure Assessment (SOFA) sub-score, need for mechanical ventilation, and 3 point lower overall SOFA score, alongside lower cardiovascular, coagulatory, renal and central nervous system sub-scores. ICU length-of-stay was reduced by $6(\mathrm{CI}-11.7$ to -0.5$)$ days in survivors $(p=0.03)$, with similar ICU mortality at 23.3 versus $22.4 \%$ [HR (CI) 1.4 $(0.6-3), p=0.41]$. Effects were preserved or strengthened by adjustment.

Near real-time registry data thus confirm previous implications of reduced COVID-19 hospitalization rates with increasing vaccination-ratio [4], and suggest an even larger effect regarding the development of critical illness by showing that less than $4 \%$ of COVID-19 patients admitted to ICU in the first 9 months of the vaccination program in Switzerland were vaccinated. Two main 


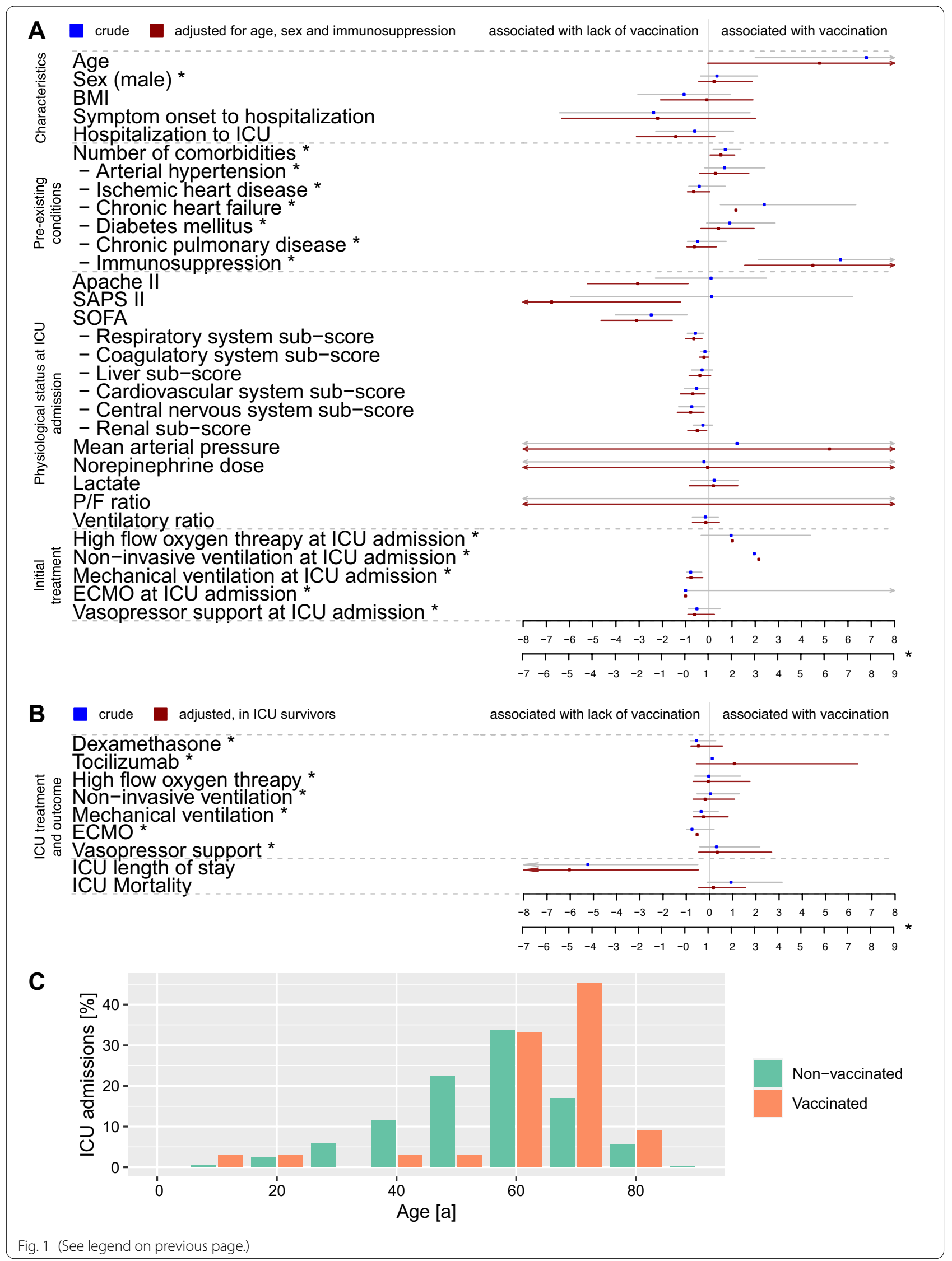




\begin{abstract}
(See figure on previous page.)
Fig. 1 Effect of vaccination status on the patient characteristics and initial treatment at ICU admission (A), and on the outcome of critically ill COVID-19 patients (B), showing for vaccinated patients admitted to the ICU, less severe lung and systemic organ failure, need for mechanical ventilation and shorter ICU length of stay, yet still similar ICU mortality despite older age and elevated risk profile. The age distribution of patients admitted to the ICU shows a marked right-shift, with only $12 \%$ of the vaccinated critically ill patients below the age of 60 years (C). Blue dots and lines represent the estimate and $95 \% \mathrm{Cl}$ of mixed model analysis with vaccination status entered as fixed effect and treatment center as random effect, whereas red dots and lines represent the estimate and $95 \% \mathrm{Cl}$ of adjusted mixed model analysis with age, sex and presence of immunosuppression-related disease as pre-existing condition as additional fixed effects. All included patients are represented in panel $(A, n=964)$, whereas panel (B) encompasses patients discharged from the ICU by September 30th, 2021 for the crude analysis graph $(n=915)$, and ICU survivors for the adjusted analysis graph $(n=710)$. ICU mortality estimates were modeled using a Cox proportional hazards model, with an underlying time scale of ICU admission until date of death or date of discharge which was defined as censoring event, with ICU mortality entered as event and ICU survival entered as censored event. Estimates are given as the mean difference (Cl) for continuous variables, RR (Cl) for counts, OR (Cl) for binary categorical variables, and $\mathrm{HR}(\mathrm{Cl})$ for survival analysis, the secondary scale applies to the reporting of RR, OR and HR as denoted (*). The vertical grey line represents the line of no effect. Estimates to the right of the grey line are associated with the vaccination, and to the left, with the lack of vaccination scilicet inversely with the vaccination. Complete results for crude and adjusted analyses in the overall and subpopulations are listed in Supplementary Table S1 and Supplementary Table S2. RR, rate ratio; OR, odds ratio; HR, hazard ratio; Cl, 95\% confidence interval
\end{abstract}

findings indicate a positive effect of the vaccination program. First, despite older age and elevated risk profile, vaccinated ICU patients had less severe lung and systemic organ failure, need for mechanical ventilation and shorter ICU length-of-stay, yet still similar ICU mortality. A trend towards higher D-dimer and lower ferritin levels could indicate differences in coagulatory activation and immune dysregulation, warranting further investigation. Second, a reduced disease severity was observed as compared to non-vaccinated patients despite an increasing prevalence of virus variants (Fig. S2 C) and reports of breakthrough infections in vaccinated individuals [5]. Nevertheless, the higher prevalence of comorbidities in vaccinated patients, together with previously described, attenuated in vitro vaccine response in immunocompromised patients, emphasize the importance of ongoing improvements to vaccination regimes, e.g., by adding booster doses.

In conclusion, our data strongly support a protective effect of the mRNA-based COVID-19 vaccines in preventing critical illness and unfavorable disease course even in patients with known risk factors for COVID19 and indicate an important role in relieving ICU resources.

\section{Supplementary Information}

The online version contains supplementary material available at https://doi. org/10.1007/s00134-021-06610-z.

\section{Author details \\ ${ }^{1}$ Institute of Intensive Care Medicine, University Hospital of Zurich, Zurich, Switzerland. ${ }^{2}$ CTU Bern, University of Bern, Bern, Switzerland.}

\section{Acknowledgements}

This work is endorsed by the Swiss Society of Intensive Care Medicine. We want to thank all nurses, physicians and other healthcare workers in our collaborating centers for their tireless and brave efforts in the care of their patients, without you this health care emergency could not be overcome. We thank Stephan M. Jakob, Yok-Ai Que, Anne-Aylin Sigg, Thierry Fumeaux, Philippe Guerci, Jonathan Montomoli, and Tanja Stadler for their invaluable help with this manuscript. The members of RISC-19-ICU Investigators for
Switzerland: RISC-19-ICU Board (Matthias P. Hilty, MD; Reto A. Schüpbach, MD; Pedro D. Wendel Garcia, MSc; Thierry Fumeaux, MD; Philippe Guerci, MD Ph.D.; Jonathan Montomoli, MD Ph.D.); Institute of Intensive Care Medicine, University Hospital Zurich, Zurich (Reto A. Schüpbach MD; Silvio Brugger, MD, Ph.D.; Jan Bartussek, Ph.D.; Sascha David, MD; Stefanie Keiser, Ph.D.; Anne-Aylin Sigg; Annelies Zinkernagel, MD, Ph.D.); Soins intensifs, Groupement Hospitalier de l'Ouest Lémanique-Hopital de Nyon, Nyon (Mallory Moret-Bochatay, MD); Interdisziplinaere Intensivstation, Spital Buelach, Buelach (Bernd Yuen, MD; Thomas Hillermann, MD); Department for Intensive Care Medicine, Kantonsspital Nidwalden, Stans (Anette Ristic, MD; Michael Sepulcri, MD); Department of Anesthesiology and Intensive Care Medicine, Cantonal Hospital St. Gallen, St. Gallen (Miodrag Filipovic, MD; Urs Pietsch, MD); Intensivstation, Regionalspital Emmental AG, Burgdorf (Petra Salomon, MD; Iris Drvaric, MD); Institut fuer Anesthaesie und Intensivmedizin, Zuger Kantonsspital AG, Baar (Peter Schott, MD; Severin Urech, MD); Intensivmedizin, St. Claraspital, Basel (Adriana Lambert, MD; Lukas Merki, MD); Department Intensive Care Medicine, Spitalzentrum Biel, Biel (Marcus Laube, MD); Intensivmedizin, Kantonsspital Graubünden, Chur (Frank Hillgaertner, MD; Marianne Sieber); Institut fuer Anaesthesie und Intensivmedizin, Spital Thurgau, Frauenfeld (Alexander Dullenkopf, MD; Lina Petersen, MD); Division of Neonatal and Pediatric Intensive Care, Geneva University Hospitals, Geneva (Serge Grazioli, MD; Peter C. Rimensberger, MD); Soins Intensifs, Hirslanden Clinique Cecil, Lausanne (Isabelle Fleisch, MD; Jerome Lavanchy, MD); Pediatric Intensive Care Unit, University Hospital Lausanne, Lausanne (Marie-Helene Perez, MD); Interdisziplinaere Intensivstation, Spital Maennedorf AG, Maennedorf (Katharina Marquardt, MD; Karim Shaikh, MD); Intensivmedizin, Schweizer Paraplegikerzentrum Nottwil, Nottwil (Hermann Redecker, MD); Intensivmedizin, Spital Oberengadin, Samedan (Michael Stephan, MD; Jan Brem, MD); Paediatric Intensive Care Unit, Children's Hospital of Eastern Switzerland, St. Gallen (Bjarte Rogdo, MD; Andre Birkenmaier, MD); Klinik für Anaesthesie und Intensivmedizin, Spitalzentrum Oberwallis, Visp (Friederike Meyer zu Bentrup, MD, MBA); Interdisziplinaere Intensivstation, Stadtspital Triemli, Zurich (Patricia Fodor, MD; Pascal Locher, MD); Department Intensivmedizin, Universitaetsspital Basel, Basel (Martin Siegemund, MD; Nuria Zellweger); Department of Intensive Care Medicine, University Hospital Bern - Inselspital, Bern (Stephan M Jakob, MD; Yok-Ai Que, MD Ph.D.; Marie-Madlen Jeitziner, RN, Ph.D.; Beatrice Jenni-Moser, RN, MSc); Interdisziplinaere Intensivmedizin, Lindenhofspital, Bern, Switzerland (Jan Wiegand, MD); Intensivstation, Spital Grabs, Grabs (Christian Bürkle, MD); Medical ICU, Cantonal Hospital St.Gallen, St. Gallen (Gian-Reto Kleger, MD); Service d'Anesthesiologie, EHNV, Yverdon-les-Bains (Marilene Franchitti Laurent, MD; Jean-Christophe Laurent, MD); Abteilung für Anaesthesiologie und Intensivmedizin, Hirslanden Klinik Im Park, Zürich (Tomislav Gaspert, MD; Marija Jovic, MD); Intensivmedizin \& Intermediate Care, Kantonsspital Olten, Olten (Michael Studhalter, MD); Institut für Anaesthesiologie und Intensivmedizin, Klinik Hirslanden, Zurich (Christoph Haberthuer, MD; Roger F. Lussman, MD); Anaesthesie Intensivmedizin Schmerzmedizin, Spital Schwyz, Schwyz (Daniela Selz, MD; Didier Naon, MD); Dipartimento Area Critica, Clinica Luganese Moncucco, Lugano (Andrea Glotta, MD; Samuele Ceruti, MD); Institut für Anaesthesiologie Intensivmedizin \& Rettungsmedizin, See-Spital Horgen \& Kilchberg, Horgen (Julien Marrel, MD; Mirko Brenni, MD); Klinik für Operative Intensivmedizin, 
Kantonsspital Aarau, Aarau (Rolf Ensner, MD; Marc Michot, MD); Intensivstation, Kantonsspital Schaffhausen, Schaffhausen (Nadine Gehring, MD); Intensivstation, Spital Simmental-Thun-Saanenland AG, Thun (Antje Heise, MD); Klinik für Anaesthesie Intensivmedizin Operationszentrum und Schmerzmedizin, Kantonsspital Muensterlingen, Muensterlingen (Tobias Huebner, MD; Thomas A. Neff, MD); Division of Intensive Care, University Hospitals of Geneva, Geneva (Sara Cereghetti, MD; Filippo Boroli, MD; Jerome Pugin, MD, Ph.D.).

\section{Funding}

This work is funded and endorsed by the Swiss Society of Intensive Care Medicine and unrestricted research grants by the Institute of Intensive Care Medicine at the University Hospital of Zurich, CytoSorbents Europe GmbH, Berlin, Germany, and Union Bancaire Privée, Geneva, Switzerland. The funders had no role in the design and conduct of the study; collection, management, analysis, and interpretation of the data; preparation, review, or approval of the manuscript; and decision to submit the manuscript for publication.

\section{Declarations}

\section{Conflicts of interest}

The authors do not report any conflicts of interest.

\section{Ethical approval}

The present report is based on the prospective, near real-time observational Risk Stratification in Covid-19 patients in the ICU (RISC-19-ICU) registry, a tool launched on March 17th, 2020, to track patient and disease characteristics and disease course of critically ill COVID-19 patients. The registry is endorsed by the Swiss Society of Intensive Care Medicine (https://www.sgi-ssmi.ch) and was exempted from the need for additional ethics approval and patient informed consent by the ethics committee of the University of Zurich (KEK 2020-00322, ClinicalTrials.gov Identifier: NCT04357275). The study complies with the Declaration of Helsinki, the Guidelines on Good Clinical Practice (GCP-Directive) issued by the European Medicines Agency as well as the Swiss law and Swiss regulatory authority requirements and has been designed in accordance with the Strengthening the Reporting of Observational Studies in Epidemiology (STROBE) guidelines for observational studies.

\section{Publisher's Note}

Springer Nature remains neutral with regard to jurisdictional claims in published maps and institutional affiliations.
Accepted: 21 December 2021

Published online: 20 January 2022

\section{References}

1. Pilishvili T, Gierke R, Fleming-Dutra KE, Farrar JL, Mohr NM, Talan DA, Krishnadasan A, Harland KK, Smithline HA, Hou PC, Lee LC, Lim SC, Moran GJ, Krebs E, Steele MT, Beiser DG, Faine B, Haran JP, Nandi U, Schrading WA, Chinnock B, Henning DJ, Lovecchio F, Lee J, Barter D, Brackney M, Fridkin SK, Marceaux-Galli K, Lim S, Phipps EC et al (2021) Effectiveness of mRNA Covid-19 Vaccine among US Health Care Personnel. N Engl J Med 385:e90

2. Hilty MP, Moser A, David S, Wendel Garcia PD, Capaldo G, Keiser S, Fumeaux T, Guerci P, Montomoli J, Van Boeckel TP, Jeitziner M-M, Que Y-A, Jakob S, Schüpbach RA, RISC-19-ICU Investigators For Switzerland (2021) Near real-time observation reveals increased prevalence of young patients in the ICU during the emerging third SARS-CoV-2 wave in Switzerland. Swiss Med Wkly 151:w20553

3. Wendel Garcia PD, Fumeaux T, Guerci P, Heuberger DM, Montomoli J, Roche-Campo F, Schuepbach RA, Hilty MP, RISC-19-ICU Investigators (2020) Prognostic factors associated with mortality risk and disease progression in 639 critically ill patients with COVID-19 in Europe: initial report of the international RISC-19-ICU prospective observational cohort. EClinicalMedicine 25:100449

4. Thompson MG, Stenehjem E, Grannis S, Ball SW, Naleway AL, Ong TC, DeSilva MB, Natarajan K, Bozio CH, Lewis N, Dascomb K, Dixon BE, Birch RJ, Irving SA, Rao S, Kharbanda E, Han J, Reynolds S, Goddard K, Grisel N, Fadel WF, Levy ME, Ferdinands J, Fireman B, Arndorfer J, Valvi NR, Rowley EA, Patel P, Zerbo O, Griggs EP et al (2021) Effectiveness of COVID-19 vaccines in ambulatory and inpatient care settings. N Engl J Med 385:1355-1371

5. Jung J, Sung H, Kim S-H (2021) COVID-19 breakthrough infections in vaccinated health care workers. N Engl J Med 385:1629-1630 